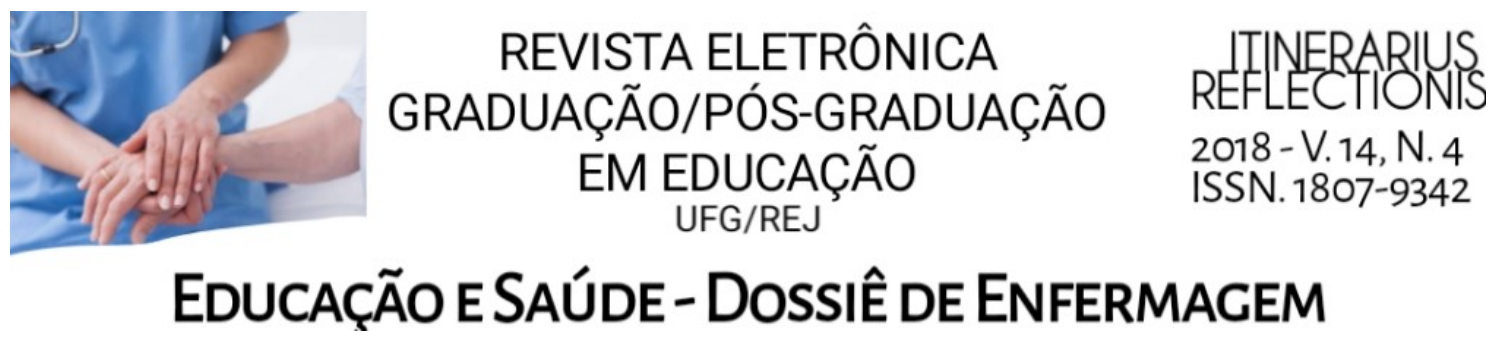

\title{
ACOLHER MAIS: RECEPÇÃO DOS CALOUROS DO CURSO DE GRADUAÇÃO EM ENFERMAGEM
}

\author{
Micaela Souza Santos ${ }^{1}$ \\ Araceli Rezende Farias Chaves ${ }^{2}$ \\ Raiane da Silva Arantes Ferreira ${ }^{3}$ \\ Samantha Ferreira da Costa Moreira ${ }^{4}$ \\ Marise Ramos de Souza ${ }^{5}$ \\ Cristiane José Borges ${ }^{6}$
}

RESUMO: Relatar a experiência vivenciada por petianos na implementação de uma atividade de recepção, acolhedora e humanizada, aos calouros do Curso de Graduação em Enfermagem. Estudo descritivo, tipo relato de experiência. A ação foi desenvolvida com 20 ingressantes no Curso de Graduação em Enfermagem da Universidade Federal de Goiás - Regional Jataí, no ano de 2017. Observou-se que a maioria (80\%) dos participantes eram do sexo feminino, com idade entre 17 e 27 anos, estado civil solteiro e provenientes do município de Jataí-Go. Os dados evidenciaram que o ato de adentrar no contexto universitário é marcado por insegurança, medo e inúmeras dúvidas, as quais puderam ser minimizadas com o desenvolvimento da atividade de extensão em questão. Constatou-se que $100 \%$ dos discentes consideraram que recepção foi humanizada e acolhedora, sendo essencial que aconteça, anualmente, na entrada de novos estudantes, pois configura como um espaço importante de interação, que pode influenciar de maneira significativa para a permaneça dos alunos no curso e na universidade.

Palavras-chave: Enfermagem; Estudantes de Enfermagem.

\section{TO WELCOME MORE: RECEPTION OF THE NURSING UNDERGRADUATE FRESHMEN STUDENTS}

\footnotetext{
${ }^{1}$ Acadêmica do Curso de Graduação em Enfermagem da Universidade Federal de Jataí. Bolsista do Programa de Educação Tutorial - PET Enfermagem Jataí. Email: micaelasantos7895@gmail.com

2 Acadêmica do Curso de Graduação em Enfermagem da Universidade Federal de Jataí. Bolsista do Programa de Educação Tutorial - PET Enfermagem Jataí. Email: aracelifariasjatai@gmail.com

${ }^{3}$ Acadêmica do Curso de Graduação em Enfermagem da Universidade Federal de Jataí. Bolsista do Programa de Educação Tutorial - PET Enfermagem Jataí. Email: raianearantes30@hotmail.com

${ }^{4}$ Enfermeira. Professora e mestre do Curso de Graduação em Enfermagem da Universidade Federal de Jataí (GO), Brasil. Email: samanthafrmoreira@hotmail.com

5 Enfermeira. Professora e doutora do Curso de Graduação em Enfermagem UFG/Regional Jataí. Tutora do Programa de Educação Tutorial - PET Enfermagem/Regional Jataí. Email: msc_marise@hotmail.com

6 Enfermeira. Professora e doutora do Curso de Graduação em Enfermagem UFG/Regional Jataí. Tutora do Programa de Educação Tutorial - PET Enfermagem/Regional Jataí. Email: cristianejose@yahoo.com.br
} 


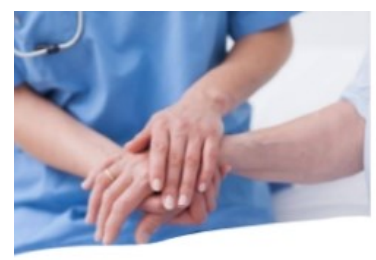

\section{REVISTA ELETRÔNICA GRADUAÇÃO/PÓS-GRADUAÇÃO EM EDUCAÇÃO UFG/REJ}

ISSN. $1807-9342$

\section{EDUCAÇ̃̃o ESAÚdE-DOSSIÊ DE ENFERMAGEM}

ABSTRACT: To report the experience lived by petianos in the implementation of a reception activity, welcoming and humanized, to the freshmen students of the Undergraduate Nursing Course. Descriptive study, experience report type. The action was developed with 20 students enrolled in the Undergraduate Nursing Course of the Federal University of Goiás - Jataí Regional, in 2017. It was observed that the majority (80\%) of the participants were female, aged between 17 and 27 years, single marital status and coming from Jataí-Go municipality. The data showed that the act of entering the university context is marked by insecurity, fear and numerous doubts, which could be minimized with the development of the extension activity in question. It was found that $100 \%$ of the students considered that the reception was humanized and welcoming, and it is essential that it happens annually in the entrance of new students, since it constitutes an important space of interaction, that can influence in a significant way the students' stay in the course and in the university.

Keywords: Nursing; Nursing students. 


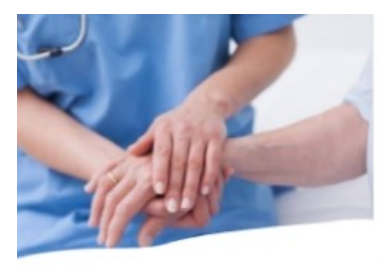

\section{REVISTA ELETRÔNICA GRADUAÇÃO/PÓS-GRADUAÇÃO EM EDUCAÇÃO} UFG/REJ

REETEERARIS

2018 - V.14, N. 4

ISSN. $1807-9342$

\section{EdUCAC̄̃̃o ESAÚdE-DOSSIÊ DE ENFERMAGEM}

\section{INTRODUÇÃO}

O ingresso em uma Instituição de Ensino Superior (IES) é um objetivo almejado por muitas pessoas, no entanto, pode ser acompanhado por inúmeras inquietações e incertezas. É compreendido como uma fase de transição que, pode ocasionar aos jovens estudantes diferentes tipos repercussões psicológicas (TEXEIRA et al. 2008).

Para Tao et. al (2000), isto se deve a inúmeros fatores, entre eles, destaca-se, o fato de está adentrando em um mundo diferente, sendo lhes exigido, muitas vezes, a tomada decisões como se fossem adultos (TAO et al, 2000). Além disso, emerge a insegurança em relação a profissão que escolheu e as transformações nas redes de amizade e de apoio social (TAO et al, 2000).

Frente a estes desafios, os ingressantes podem reagir de maneiras diferentes ocasionando, em muitos casos, a sua dificuldade em relação ao convívio social no ambiente universitário. Assim, um ambiente acolhedor pode ser o diferencial para a inclusão do aluno nos círculos sociais existentes (TAO et al, 2000).

Por outro lado, observa-se que o indivíduo ao se matricular na IES é submetido ao tradicional ritual de passagem, o trote, que se torna um acontecimento marcante na vida do acadêmico, pois será a sua primeira impressão diante da nova realidade (TEIXEIRA et al., 2008).

Nesta perspectiva, a literatura mostra que um estudante que tem sua entrada na IES de forma tranquila, integrativa e acolhedora possui maiores chances de conviver melhor socialmente e de crescer intelectualmente e pessoalmente (TEIXEIRA et al., 2008).

$\mathrm{O}$ ato de acolher os calouros pode ser compreendido, muitas vezes, como apenas uma questão de hospitalidade, entretanto, a literatura mostra que vai além disso, trata-se de uma oportunidade para construir um espaço fenomênico, possibilitando estabelecer uma relação entre os sujeitos que acolhem e os que são acolhidos, o que consequentemente favorece para os sentimentos de empatia e interação entre os envolvidos (SANTOS; PERAZZOLO; PEREIRA, 2014). 


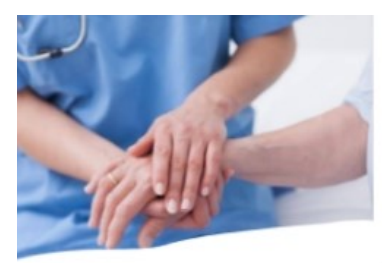

\section{REVISTA ELETRÔNICA GRADUAÇÃO/PÓS-GRADUAÇÃO EM EDUCAÇÃO} UFG/REJ

REFINERARIUS

2018 - V.14, N. 4

ISSN. $1807-9342$

\section{EdUCAÇÃo ESAÚdE-DossiÊ DE ENFERMAGEM}

De acordo com Boff (2006), para que alguém seja efetivamente acolhido é preciso que aqueles que acolhem sejam capazes se desprenderem de preconceitos, o que viabilizará para que se construa um diálogo empático e efetivo. Vale mencionar que o ato de acolher é amplo, mas destaca-se na necessidade de proteger, abrigar e amparar o outro (HOUAISS, 2001).

A comunicação estabelecida pela empatia entre veteranos e calouros pode ser um fator determinante para que se suscite um dialogo mais fluido, com minimização das possíveis diferenças (SANTOS; PERAZZOLO; PEREIRA, 2014). Assim, torna-se notório que o estimulo e a integração social dos estudantes é de suma importância, uma vez que a IES tem um papel fundamental na formação da identidade dos novos universitários, bem como, na construção de uma rede de apoio ao acadêmico, a fim de auxiliá-lo frente às necessidades e desafios (TEIXEIRA, 2008).

Nesta perspectiva, o presente estudo tem como objetivo relatar a experiência vivenciada por petianos na implementação de uma atividade de recepção, acolhedora e humanizada, aos calouros do Curso de Graduação em Enfermagem.

\section{METODOLOGIA}

Trata-se de uma pesquisa descritiva baseada no relato de experiência de uma ação voltada para os discentes ingressantes no Curso de Graduação em Enfermagem da Universidade Federal de Goiás (UFG) - Regional Jataí,

O projeto intitulado "Acolher mais: recepção dos calouros do Curso de Graduação em Enfermagem" foi idealizado pelo Grupo do Programa de Educação Tutorial (PET) Enfermagem-UFG/Regional Jataí, o qual é composto por quatorze membros, sendo uma tutora, uma professora colaboradora e doze petianos bolsistas. A ação foi realizada no primeiro semestre letivo do ano de 2017. E para tal, utilizou-se o espaço físico do laboratório de enfermagem localizado no prédio da Biomedicina e Enfermagem da UFG.

Inicialmente, foi elaborado um convite impresso para os ingressantes, contendo 


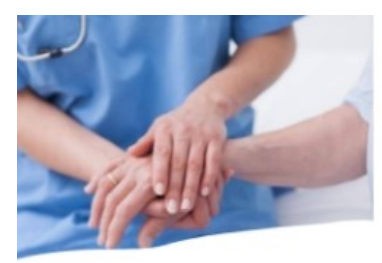

\section{REVISTA ELETRÔNICA GRADUAÇÃO/PÓS-GRADUAÇÃO EM EDUCAÇÃO} UFG/REJ

REEENERARIONS

2018 - V.14, N. 4

ISSN. $1807-9342$

\section{EDUCAÇ̃̃o ESAÚdE-DOSSIÊ DE ENFERMAGEM}

data, local e horário. O mesmo foi entregue aos ingressantes antecipadamente, sendo explicado aos mesmos sobre a importância de sua participação na ação proposta. A atividade foi implementada em dois momentos.

O primeiro momento aconteceu em um dos laboratório do curso supracitado, sendo realizado a apresentação dos novos ingressantes, por meio de uma técnica de acolhimento e integração. Nesta, constava questões que permitiam que os calouros se apresentassem, bem como, manifestassem os seus anseios e sentimentos em relação à nova realidade e ao contexto universitário.

A técnica de acolhimento sucedeu-se da seguinte maneira: entregou-se a cada um dos participantes cartões contendo os seguintes tópicos: nome, idade, motivo pelo qual escolheu o curso de enfermagem, suas expectativas para com a universidade, suas angústias com essa nova fase, um sonho e, por último, se eles conheciam o PET Enfermagem.

Após todos responderem por escrito as indagações, os papéis foram colocados em um recipiente, a fim de que os participantes o retirassem aleatoriamente $\mathrm{e}$ apresentassem o outro colega. No decorrer da leitura dos cartões, o estudante que estava sendo referido não poderia se manifestar, sendo estimulado que os demais participantes adivinhassem a quem corresponderia tais características.

Em seguida, oportunizou-se um momento para que cada um dos ingressantes cumprimentasse verbalmente todos os presentes. Após as apresentações dos ingressantes, estes receberam um pirulito com mensagem de boas vindas, devendo este ser entregue ao colega que leu o cartão com suas características.

Logo após, os docentes recepcionaram os calouros com mensagens acolhedoras e explicitações sobre a importância de ser enfermeiro, além de explanarem um breve relato sobre sua área de atuação e as disciplinas que ministram no decorrer do curso.

Posteriormente, a coordenação do curso, representada pela coordenadora e pelo secretário do curso explicaram sobre o funcionamento da estrutura curricular do curso e sobre a função e formas de uso do SIGAA (Sistema Integrado de Gestão de Atividades Acadêmicas), o qual é fundamental para a vida acadêmica dos alunos. 


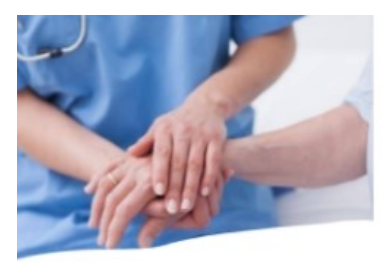

\section{REVISTA ELETRÔNICA GRADUAÇÃO/PÓS-GRADUAÇÃO EM EDUCAÇÃO} UFG/REJ

REEENERARIONS

2018 - V. 14, N. 4

ISSN. $1807-9342$

\section{EdUCAÇÃo ESAÚdE-DOSSIÊ DE ENFERMAGEM}

Além disso, tendo em vista atender os pilares da universidade: ensino, pesquisa e extensão contou-se com a apresentação de docentes representantes de comissões, câmara técnicas, núcleo docente estruturante, núcleos de pesquisas e PET. Estes abordaram de maneira sucinta as especificidades, assim como, a imprescindibilidade de desenvolver todas as atividades da tríade no decorrer dos cinco anos de graduação.

Para finalizar a primeira etapa da programação, os bolsistas do grupo PET discorreram sobre os objetivos e funcionamento do programa, o qual fazem parte. E também exibiram um vídeo ilustrando os projetos de ensino, pesquisa e extensão executados pelos membros do grupo ao longo dos seis anos em que este foi instituído na UFG/ Regional Jataí.

Para iniciar as atividades delineadas para segunda etapa do evento, distribui-se aos participantes um protetor solar, a fim de protegê-los dos raios solares no decorrer das ações propostas ao ar livre, sendo estas: a) o plantio de duas mudas de árvores Ypê na área de distribuição do prédio da Biomedicina e Enfermagem e b) caminhada tendo como trajetória os principais espaços físicos a ser utilizados pelos ingressantes no curso de enfermagem. Além de demonstrar a localização desses lugares, realizou-se também uma breve explicação do funcionamento dos mesmos, no intuito de minimizar os anseios e as principais dúvidas dos calouros.

Os promotores da ação, no decorrer do percurso efetivaram uma técnica intitulada como: "caça ao tesouro", uma vez que, no trajeto haviam brindes escondidos e que tinham que ser encontrados, após algumas dicas, pelos participantes. No total, foram distribuídos quatro brindes, sendo esses: a) um livro científico, cuja temática retratava questões relacionadas ao HIV/Aids; b) dois sabonetes corporais e c) um sabonete líquido para as mãos.

A caminhada encerrou-se no Restaurante Universitário (RU), com a finalidade de promover uma almoço de integração entre calouros e veteranos. Vale ressaltar que, antes da chegada dos calouros, dois membros da equipe promotora organizou o espaço físico do referido restaurante, disponibilizando as mesas e cadeiras de modo em que permitisse uma maior interação entre os participantes da ação. 


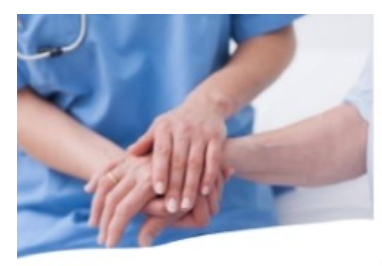

\section{REVISTA ELETRÔNICA GRADUAÇÃO/PÓS-GRADUAÇÃO EM EDUCAÇÃO} UFG/REJ

REFLEERARIUS

$2018-$ V.14, N. 4

ISSN. 1807-9342

\section{EduCAÇÃo ESAÚdE-DOSSIÊ DE ENFERMAGEM}

Após o almoço, solicitou-se aos ingressantes que respondessem um questionário. Este constitui-se de questões referentes a caracterização do perfil dos ingressantes e perguntas referentes à sua opinião sobre a atividade desenvolvida.

Essas informações foram utilizadas para subsidiar a continuidade do apoio do grupo promotor do evento aos calouros e como suporte para o relato de experiência. Os dados evidenciados foram sistematizados e analisados mediante o uso de frequência absoluta e relativa e agrupamento das opiniões/ satisfações.

\section{RESULTADO E DISCUSSÃO}

Ingressam, anualmente, no Curso de Graduação em Enfermagem - UFG Regional Jataí 30 alunos, no entanto, no dia da implementação do presente projeto participaram 20 desses. Os dados revelaram que $80 \%$ (n.16) dos calouros eram do sexo feminino e $20 \%$ (n. 04) do sexo masculino.

Sabe-se que desde a antiguidade, a enfermagem é uma profissão que carrega o estereótipo de gênero, pensada como feminina devido ao contexto histórico-social, em que a igreja determinava que os cuidados de enfermagem aos enfermos fossem exercidos exclusivamente ou majoritariamente por mulheres por serem consideradas mulher-mãe e assim, enfermeiras natas (CUNHA; SOUSA, 2017).

As evidências mostram que a partir dos anos 90, o quantitativo de enfermeiros do sexo masculino vem aumentando consideravelmente, porém, muitos homens preferem não ingressar em profissões vistas como femininas e escolhem aquelas de maior poder e prestígio social, a fim de não serem discriminados, vistos como inferiores ou questionados quanto sua à orientação sexual (CUNHA; SOUSA, 2017).

Em relação à faixa etária, observou-se que $90 \%$ (n.18) dos entrevistados tinham idade de 17 a 27 anos e 10\% (n. 02) de 28 à 40 anos. Corroborando com os dados recentes do Censo da Educação Superior que mostram que cerca da metade dos 7 


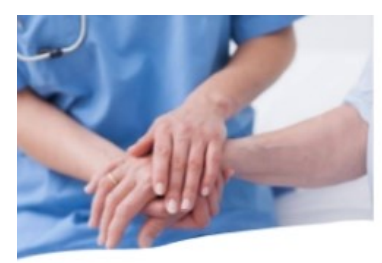

\section{REVISTA ELETRÔNICA GRADUAÇÃO/PÓS-GRADUAÇÃO EM EDUCAÇÃO} UFG/REJ

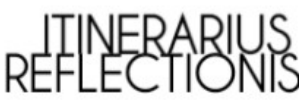

2018 - V. 14, N. 4

ISSN. $1807-9342$

\section{EDUCAÇ̃̃o ESAÚdE-DOSSIÊ DE ENFERMAGEM}

milhões de estudantes têm mais de 20 anos de idade e que, destes, cerca de 600 mil têm mais de 40 anos de idade. Para Corrêa et al. (2011) a faixa etária dos estudantes que iniciam um curso de graduação em IES compreende entre18 e 24 anos.

Quanto a naturalidade dos calouros de enfermagem, constatou-se que 55\% (11) são provenientes do município de Jataí e 45\% (09) de outros municípios do Estado Goiás e de Pernambuco. A maioria 60\% (12) dos pesquisados referiram residir no município de Jataí antes de serem aprovados na IES e 40\% (08) responderam que mudaram para o município após o resultado positivo no processo seletivo para cursar a graduação em enfermagem na UFG.

Conhecer tais dados é de suma importância para os membros promotores do evento, pois como se trata de uma proposta de uma recepção acolhedora e humanizada, a perspectiva é que o suporte social e acadêmico aos ingressantes continue após a realização da atividade, principalmente até o final do primeiro período de curso, pois acredita-se que esse seja um tempo razoável para a adaptação dos novos estudantes à universidade.

Por outro prisma, o ato de organizar um evento para recepcionar os ingressantes no Curso de Graduação em enfermagem, inicialmente, foi considerado pelos bolsistas do PET como um desafio, pois não conheciam as características especificas do público alvo. Entretanto, a organização foi pautada nos relatos de perfis dos acadêmicos de enfermagem que constam na literatura (SPINDOLA; MARTINS; FRANCISCO, 2008). Apesar das angústias da equipe organizadora, os calouros foram extremamente receptivos e participativos em todas as atividades propostas, como mostram as figuras 1 e 2.

Figura 1: Caminhada dos ingressantes na perspectiva de conhecer a universidade 


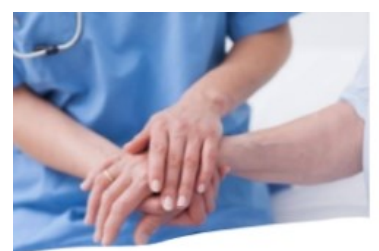

\section{REVISTA ELETRÔNICA GRADUAÇÃO/PÓS-GRADUAÇÃO EM EDUCAÇÃO UFG/REJ}

\section{EDUCACÃo ESAÚdE-DOSSIÊ DE ENFERMAGEM}

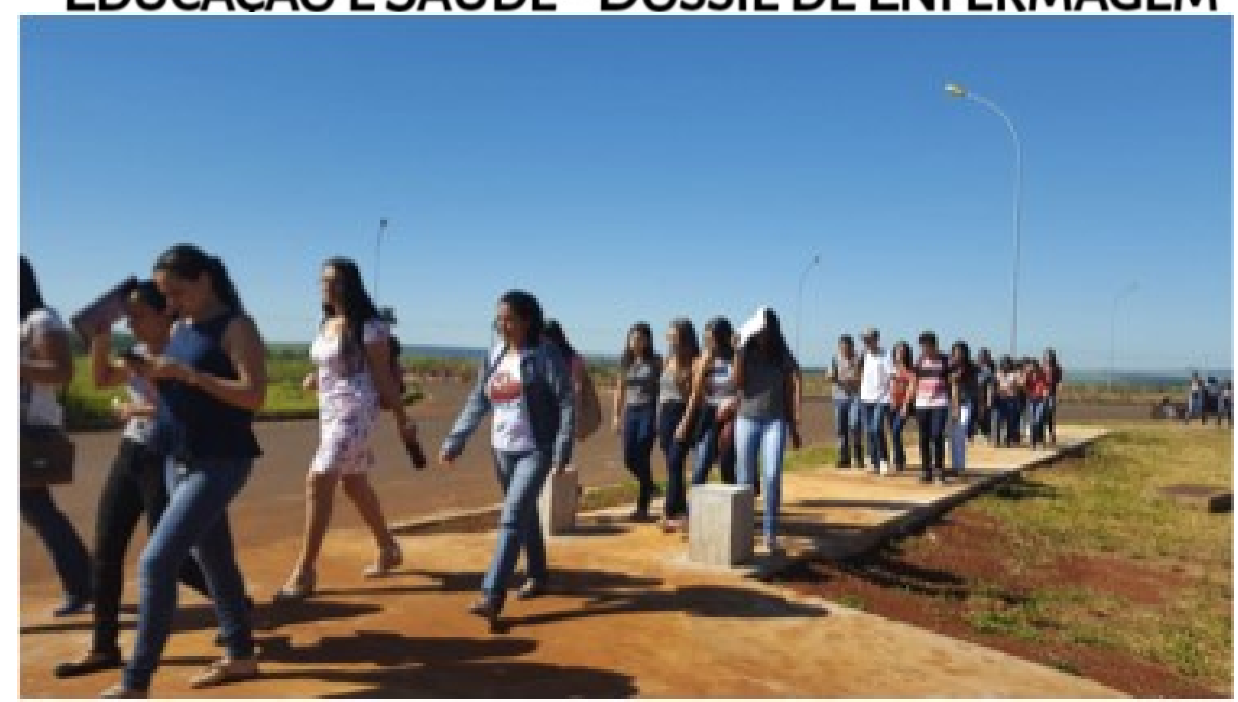

Fonte: Arquivo dos autores, 2018.

Figura 2: Ingressantes plantando a árvore como símbolo da sua turma

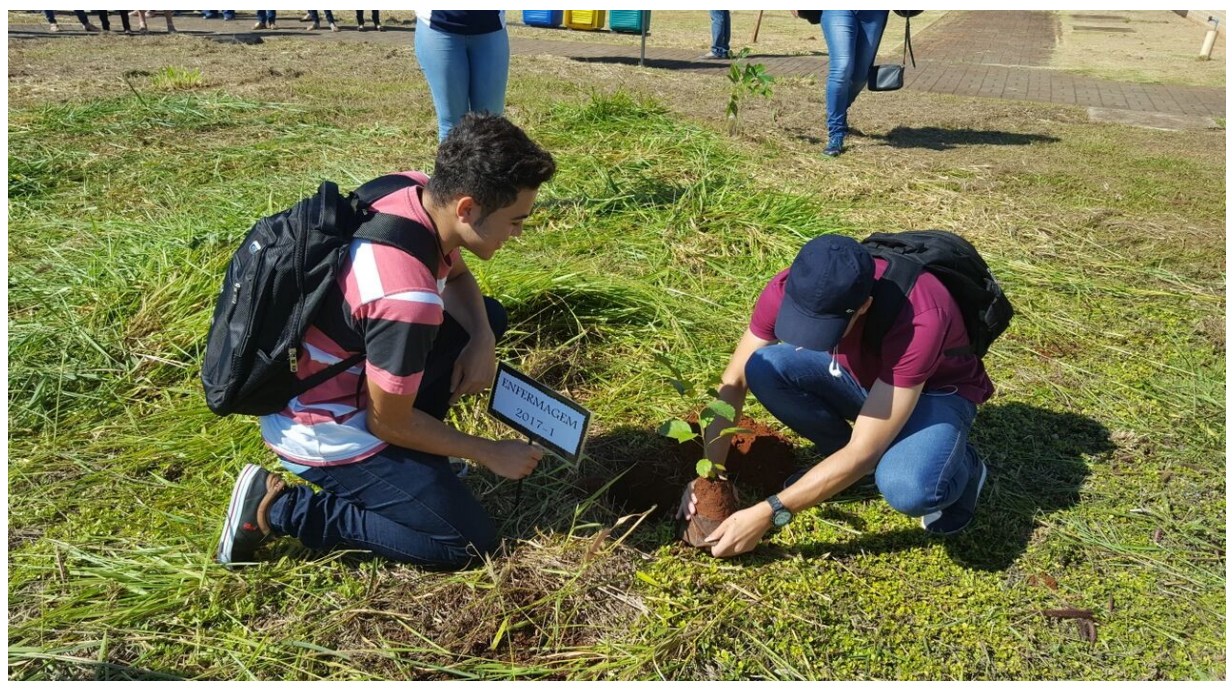

Fonte: Arquivo dos autores, 2018.

Observou-se que na opinião da maioria (60\%) dos ingressantes do Curso de Graduação em Enfermagem, a maneira em que foram recepcionados possibilitou o esclarecimento de dúvidas e minimizou diversos anseios. 


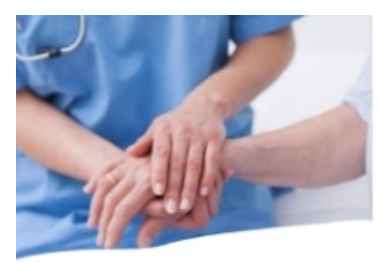

\section{REVISTA ELETRÔNICA GRADUAÇÃO/PÓS-GRADUAÇÃO EM EDUCAÇÃO UFG/REJ}

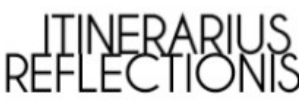

2018 - V. 14, N. 4

ISSN. $1807-9342$

\section{EDUCAÇÃo ESAÚdE-DOSSIÊ DE ENFERMAGEM}

O desenvolvimento do projeto foi considerado pelos discentes (100\%) como uma recepção humanizada e acolhedora, sendo essencial que aconteça, anualmente, na entrada de novos estudantes, pois configura como um espaço importante de interação, que pode influenciar de maneira significativa para a permaneça dos alunos no curso e na universidade.

Além disso, verificou-se que $75 \%$ (n.17) dos ingressantes considerou integrativo a prática de um almoço no restaurante universitário, o qual possibilitou o estreitamento do contato entre eles e os veteranos do curso em questão.

Ao final do questionário, os usuários tiveram um espaço para escrever sugestões e comentários a respeito do presente projeto. Abaixo estão descritos alguns relatos demonstrando que os calouros sentiram se contentes da maneira em que foram recebidos no contexto universitário:

"Gostei bastante do projeto. Espero participar futuramente" (C1).

"O projeto de extensão é muito interativo, acolhedor e explicam muito bem" (C12).

"Gostaria de agradecer pela receptividade, me deixou menos apreensiva e me ajudou a interagir com meus colegas de curso" (C17).

Para Costa et. al. (2017) pode-se destacar inúmeros pontos positivos na recepção acolhedora dos calouros, entre eles: 1) O estreitamento das relações entre a IES e o estudante; 2) Redução nos números de evasão dos discentes; 3) Estabelecimento de vínculo entre ingressantes, veteranos, docentes e demais servidores.

Ainda para os autores supracitados, as iniciativas de recepcionar, humanizadamente, os novos estudantes é fundamental para interromper com a cultura dos trotes violentos e humilhantes e autoritários, bem como, o bullying nas instituições de ensino, propiciando assim, um ambiente escolar mais socializador e humanizador (COSTA et.al., 2017). 


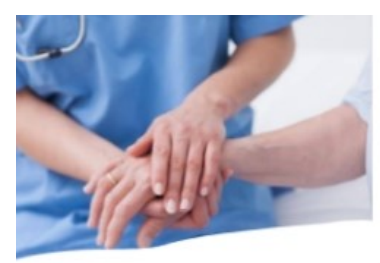

\section{REVISTA ELETRÔNICA GRADUAÇÃO/PÓS-GRADUAÇÃO EM EDUCAÇÃO UFG/REJ}

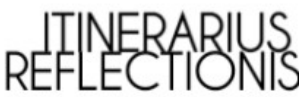

2018 - V. 14, N. 4

ISSN. $1807-9342$

\section{EDUCAÇ̃̃o ESAÚdE-DOSSIÊ DE ENFERMAGEM}

\section{CONSIDERAÇÕES FINAIS}

A experiência de organizar um evento para recepcionar os ingressantes no Curso de Graduação em enfermagem, de maneira acolhedora e humanizada foi essencial para motivar os estudantes veteranos a se sentirem confiantes em realizar ações com esta finalidade. Além disso, os despertou para a necessidade de manter um ambiente universitário harmonioso e socializador, o que consequentemente oportuniza a troca de conhecimento e/ experiências.

Outro aspecto essencial que deve ser mencionado é que, o acadêmico de enfermagem ao participar de atividades com o foco voltado para a humanização contribui significativa para sua formação enquanto profissional enfermeiro com o desenvolvimento das competências e habilidades de relações interpessoais.

Além disso, acredita-se que a recepção humanizada pode minimizar a evasão dos discentes ingressantes, aumentando o envolvimento desses indivíduos tanto com a universidade quanto com o curso de graduação escolhido.

\section{REFERÊNCIAS}

BOFF, L. Virtudes para um outro mundo possível: Convivência, respeito e tolerância. Petrópolis: Vozes, 2006.

COSTA, R.A.C. et. al. Recepção cidadã: uma experiência de construção de relações humanizadas visando à permanência e êxito estudantil no IFTM Campus Uberlândia. In: MARTINS, A.P. et al. (org). Processos e práticas de ensino no IFTM: o acesso, a permanência e o êxito dos estudantes. Uberaba: Instituto Federal do Triângulo Mineiro, 2017. p.79-92.

CORREA, A. K. et al . Perfil de estudantes ingressantes em licenciatura: Escola de Enfermagem de Ribeirão Preto da Universidade de São Paulo. Rev. esc. enferm. USP, São Paulo, v. 45, n. 4, p. 933-938, 2011.

CUNHA, Y. F. F.; SOUSA, R. R. Gênero e enfermagem: um ensaio sobre a inserção do homem no exercício da enfermagem. Revista de Administração Hospitalar e Inovação em Saúde, v. 13, n. 3, p. 140-9, 2016.

HOUAISS, A. Dicionário Houaiss de Língua Portuguesa. Rio de Janeiro: Objetiva, 2001. 

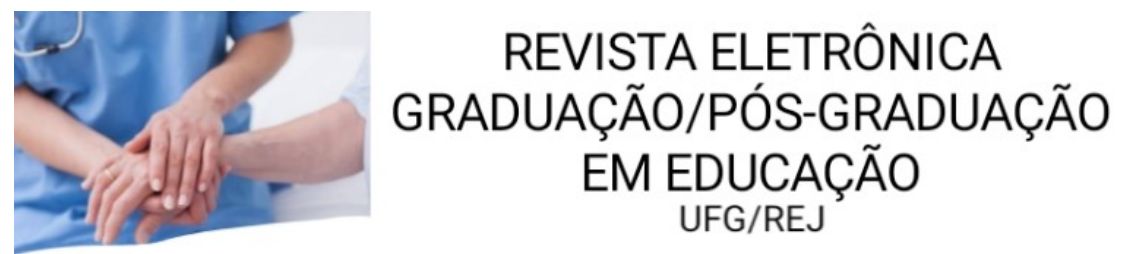

REVISTA ELETRÔNICA

EDUCAÇÃo ESAÚDE-DOSSIÊ DE ENFERMAGEM

A,T; MARTINS, E.R.C; FRANCISCO, M.T.R. Enfermagem como opção: perfil de graduandos de duas instituições de ensino, Brasília, v. 61, n.2, p.164-169, 2008.

SANTOS, M. M. C.; PERAZOLLO, O. A.; PEREIRA, S. A hospitalidade numa perspectiva coletiva o corpo coletivo acolhedor. In: SANTOS, M. M. C.; BAPTISTA, I. (org.). Laços sociais: por uma epistemologia da hospitalidade. Caxias do Sul: Educs, 2014. p. 49-63.

TEIXEIRA, M. A. P. et al. Adaptação à universidade em jovens calouros. Revista Semestral da Associação Brasileira de Psicologia Escolar e Educacional, v. 12, n. 1, p. 185-201, 2008.

TAO, S. et al. Social support: Relations to coping and adjustment during the transition to university in the People's Republic of China. Journal of Adolescent Research, v. 15, n. 1, p. 123-44, 2000. 